H. H. Paine. Letters to the Editor and Notes and News are given reasonable space, and there is a further article, "The Control of Reverberation in Theatres and Concert Halls", by Prof. P. R. Kirby. An account of the Oudtshoorn meeting of the South African Association completes the number. The editor of South African Science is Dr. H. B. S. Cooke, of the Dopartment of Geology, University of the Witwatersrand, who is to be congratulated on the first number of a journal which is clearly needed in such a rapidly developing area as South Africa.

\section{The Indian Archives}

The Indian Archives, the first number of which, dated January 1947, has just been received, is a welcome addition to periodical literature on documentation and to the specialist journals of India; its high quality is assured by the fact that it is published by the Imperial Record Department at New Delhi on behalf of the Indian Historical Records Commission. Since the establishment of the Imperial Record Department in 1891 and the Records Commission some thirty years later, much has been achieved, as reference to their many publications will show, in the collection and systematic classification, calendaring and indexing of the Government of India's extant records and in the technical work of their proper care and preservation. But much remains to be done. There are still many districts in India with an untold wealth of valuable archives in charge of unqualified keepers, and some Provinces and States without central record offices. India is not the only country that has in the past been indifferent to the value of its historical records. There, as elsewhere, healthy signs exist of an awakening of the public conscience, and the new journal is intended not only to stimulate this but also to serve as a clearing house for scientific knowledge on matters of archival interest and as an advice and information centre for Indian archivists. The editorial board proposes to print important articles on archival subjects from the foreign press as well as original contributions and papers dealing with India's special problems. This first number has a very interesting selection ; it is well produced and will be well received by all concerned with archives and their keeping. It is to appear quarterly.

\section{A New Mycological Periodical}

THE well-known periodical Annales Mycologici, beginning in 1903, ended with its forty-second volume. The premises of the publisher were destroyed in an air attack in April 1945, and H. Sydow, the editor and founder of the journal, died in the following year. Dr. F. Petrak, the eminent mycologist of the Vienna Museum, has decided to re-start the journal with the title Sydowia. It will retain its international character and will appear twice a year, each number containing $12-15$ sheets. The first number is to be published this year and will include some papers by Petrak which were contained in Nos. 3-6 of Vol. 42 of the Annales, the whole edition of which was destroyed. Mycologists are invited to send original articles for publication in English, French, German, Italian, Latin or Spanish. The price of each volume will be 40 Swiss francs. The publisher is Ferdinand Berger, Horn, Nied.-Osterreich ; the editor, Dr. F. Petrak, Botanische Abteilung des Naturhistorischen Museums, Vienna, Austria. British mycologists will wish Dr. Petrak success in his venture.

\section{Chymia}

The great interest shown in the United States in the history of science is to find a further expression in the inauguration towards tho end of this year of an annual publication on historical chemistry, entitled Chymia. It is anticipated that each volume will contain about a dozen articles of some four to five thousand words each, written in various languages and contributed by leading authorities from all over the world. It is appropriate that Chymia should be sponsored by the Edgar Fahs Smith Memorial Collection at the University of Pennsylvania, for it was in this University that the first American chair of chemistry was established in 1769 , in the Colonial period, and filled by Benjamin Rush, one of Joseph Black's earliest pupils at Edinburgh. The editorin-chief of Chymia is Prof. Tenney L. Davis, with a board of five other American editors and a group of consulting editors of international repute, represent ing, to date, the United States, Great Britain France, Switzerland, Sweden, Holland, Germany, the Argentine, Brazil and China. The British contributors to the first volume are Prof. J. R. Partington, Prof. John Read and Dr. F. Sherwood Taylor. The secretary of the editorial board is Miss Eva V. Armstrong, curator of the Edgar Fahs Smith Collection, University of Pennsylvania Philadelphia. Publication in Britain will be undertaken by the Oxford University Press.

\section{Summer School in Physical Chemistry at Cam- bridge}

DESIGNED to bring industrial research into closer contact with academical research, an eight-day course of lectures and class work was opened in the Department of Physical Chemistry at Cambridge on August 16. The pressure of applications induced the organisers to accommodate 180 rather than the 100 applicants originally contemplated. An unexpectedly high number of representatives came from university colleges, technical colleges and schools. Many officers attended from the research departments of the Ministry of Supply, and some from the Services. The majority were drawn from industrial organisations, headed in by a group of twenty-six from various sections of Imperial Chemical Industries, Ltd. Prof. Norrish's inaugural lecture on the history of chemistry at Cambridge was followed by eighteen lectures given by him and his staff and devoted in equal numbers to molecular structure, its quantal interprotation, its optical investigation and its bearing on pure liquids and solutions; polymerization, oxidations, explosions, photochemical reactions and nuclear chain processes; the mechanism of friction, wear and lubrication, and the induction of chemical change by impact. The course was characterized by a friendly exchange of difficulties between those attending the school and those responsible for it, and by the variety of new experimental techniques available for trial. The final meeting was attended by the Vice-Chancellor and addressed by Mr. A. V. Alexander, Minister of Defence.

\section{Libraries and their Use}

SOME of the papers read at the week-end con. ference of the London and Home Countios Branch of the Library Association held at Eastbourne in October 1946, which have now been issued as a sep.arate reprint (Library Association, 68 Holloway Road, London, N.7. 5s.), although addressed 